\title{
Research on Design and Application Method of Stereoscopic Teaching Materials
}

\author{
Wei Wang \\ School of Information Science and Technology \\ Northeast Normal University \\ The ministry of education of digital learning support \\ technology engineering research center \\ Changchun, China \\ Jingwen Pang \\ School of Information Science and Technology \\ Northeast Normal University \\ The ministry of education of digital learning support \\ technology engineering research center \\ Changchun, China
}

\author{
Yewei Tang \\ School of Information Science and Technology \\ Northeast Normal University \\ The ministry of education of digital learning support \\ technology engineering research center \\ Changchun, China
}

Jianxin Shang

The northeast normal university ideal software co., LTD,

Changchun, China

\begin{abstract}
With the strong exploration of information technology on subject teaching, the increasing effectiveness of information technology in subject teaching is increasing. As a new digital learning environment, stereoscopic teaching materials in the role of vocational education began to take shape. Firstly, this paper introduces the structure and elements of stereoscopic teaching materials, and then puts forward the application method based on case analysis in the combination of theory and practice of vocational education.
\end{abstract}

Keywords-stereoscopic teaching materias; digital learning environment; application methods

\section{INTRODUCTION}

Developing vocational education is an important way to promote economic development, Promoting employment, improving people's livelihood, solving the "three rural" is the key to ease the contradiction between labor supply and demand, we must take the development of vocational education in a more prominent position. With the rapid development and popularization of information technology, the teaching mode and the way of learning in education and teaching have also undergone earth-shaking changes, and covering an increasingly wide not only in basic education and higher education, many of the vocational education has gradually formed a teaching model of information technology. With the introduction of the concept of stereoscopic teaching materials for the first time by the National Higher Education Press in 2002, a series of applied theories have been validated in the classroom teaching practice of secondary vocational education. At present, there are many related studies on the stereoscopic teaching materials [1], [2], [3], [4], because of the requirements of stereoscopic teaching materials on their own hardware and student starting level, and the character that their own model is more suitable for the theory and practice integrated teaching mode, making it more suitable for Secondary vocational education and higher vocational education to apply.

\section{STEREOSCOPIC TEACHING MATERIAS FUNCTIONAL DESIGN}

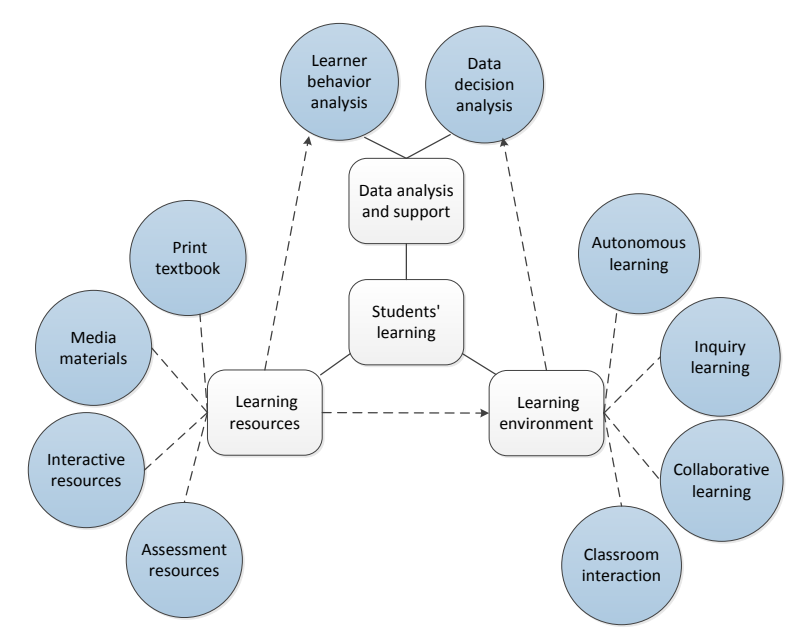

Fig. 1. Structure of stereoscopic teaching material

The stereoscopic teaching material is a teaching material composed of print textbooks, media materials (such as augmented reality technology, virtual simulation technology, learning analysis technology and intelligent diagnosis technology), environment and service. Stereoscopic teaching material takes print textbooks as its main carrier and takes students' deep learning as its purpose; it includes learning resources, ubiquitous learning environment and data analysis and support. Among them, learning resources provide support for all kinds of learning in the learning environment; with learning resources and learning environment, students' learning 
behavior can be recorded and analyzed by data, characteristics can be found, suitable learning programs can be provided, personalized learning can be supported, and optimization of teaching process and appropriate intervention can be offered in "Fig. 1".

\section{A. Print Textbook}

It is the main carrier of stereoscopic teaching material and the core of curriculum teaching material. It can be scanned by digital equipment and flexibly linked with curriculum learning resources, ubiquitous learning environment, and data analysis and support.

\section{B. Learning Resources}

It includes print textbook, media materials, interactive resources and assessment resources. Each scanning mark has a corresponding learning resource, which is generally on video resource. The media materials include text, picture, video and other types of materials. Picture and video mainly revert to the content of print textbook in a concrete and visual manner appearing in front of learners; interactive resources mainly refer to the interactive virtual simulation software, it can simulate reality to the operating environment, components, tools, machinery and so on. students can operate in a virtual reality environment to complete the transformation from textbook knowledge to application knowledge and the development from knowledge to application ability; assessment resources mainly refer to the practice and testing resources, which is the so-called "resources database". Through a lot of evaluation, students will have enough cognition to master the degree and application ability of their own knowledge, and make targeted training to consolidate knowledge according to their specific situation and needs.

\section{Learning Environment}

It mainly includes autonomous learning environment, inquiry learning environment, collaborative learning environment and classroom interaction environment. Autonomous learning environment is mainly based on the mobile terminal to provide support for the learning of students. Based on scanning the mark of print textbook by the terminal App, students can enter into the personal learning environment; they can customize the pace of their personal learning. The main contents include safety education, equipment and instrument learning, case observation, situational experience, business operation process, knowledge and skills testing, etc. Autonomous learning environment will record students' complete learning. Inquiry learning environment includes discipline tools, cognitive tools, research situation and the virtual simulation laboratory for students to carry out research activities. Students can carry out inquiry activities and process information by using discipline tools and cognitive tools, and simulate experiment by virtual simulation laboratory to test their hypothesis. Then find problems, learn self-thinking and creating in the process of their inquiry. Collaborative learning environment includes resources package, collaborative learning platform, interactive discussion space, share files and test platform for group files and collaborative process records, etc. Learning teams can assign tasks by using the interactive discussion space of collaborative learning environment. Each team can use the resources package to complete the learning task efficiently on the collaborative learning platform, and exchange or share their learning results in the sharing area. The collaboration processes can be recorded simultaneously in collaborative learning environments. Classroom interaction environment provides a strong support for classroom learning activities. It mainly divided into two dimensions, which are teaching environment and learning environment. Teachers can monitor the student terminal, maintain classroom discipline, and make classroom interaction, push and share of learning resources and students' individual learning outcomes. Students can use the terminal to submit some requests in the classroom, such as requiring answering questions or asking questions. They can also give feedback to teacher in time and get some specific suggestions in the learning process. And they can also form a learning community to research and explore learning tasks, communicate and share learning results.

\section{Data Analysis and Support}

It mainly includes the analysis of students' learning behavior and data decision, students' learning in the learning environment mainly refers to the detailed activity record of students' learning behavior about the use of learning starting point, learning content, learning speed, learning progress, autonomous learning activities, the use of resources (resource type preferences, length of time, timing of use, etc. in autonomous learning environment. Data decision can have a data analysis, excavate students' learning style, interest, aptitude, emotional attitude and character...... recommending suitable learning programs for students, providing the basis for personal development, while exploring students' group characteristics and knowledge and skills, in order to provide decision support for the optimization of the teaching process and appropriate intervention.

\section{ANALYSIS ON THE APPLICATION METHOD OF STEREOSCOPIC TEACHING MATERIAL}

Based on the 20 cases of X City Y School, this study puts forward the application method of three-dimensional teaching materials through classroom observation.

\section{A. Teaching Process}

General process: review the old knowledge into new knowledge-> teaching \&learning new knowledge-> assignment homework or task-> students' simulation operation-> students training operation-> evaluate learning outcomes.

\section{B. Teaching Behavior}

1) The general teaching behavior about teacher's explanation of knowledge: Teacher poses problems-> students themselves use pads to scan AR logo to watch the video-> teacher asks questions-> students answer questions-> teacher controls the students' pads unified again to see the video-> teacher explains knowledge.

2) The application function of stereoscopic teaching materials by teacher: Teacher uses the classroom interactive function for online roll call, screen demonstration, student 
practice results show, push resources, questions, remote shutdown, etc., by locking the students' screens to maintain classroom discipline, through the evaluation function to the students' in-class evaluation.

3) The application of multimedia by teacher: When reviewing of old knowledge and teaching of new knowledge, generally, teacher will scan AR logo in the paper textbook to obtain the explanation video, in which the knowledge principle and practical operation chart of the explanation will be presented by PowerPoint, and also will be explained with the help of physical components, if necessary, teacher will draw the wiring diagram of the circuit diagram on the blackboard again; In the simulation training operation, the interactive virtual simulation tool software of stereoscopic teaching materials will be used to simulate the wiring process and mechanical sound ; n the evaluation stage, teacher will use the pad camera function to record the students' learning outcomes of training operation.

\section{Learning Behavior}

1) Students themselves watch: Generally, there are two situations when students see the explanation video by themselves. One is to review the old knowledge, most students will see at most one time, some students will not see even once; another is to learn new knowledge, the students usually watch with the questions raised by the teacher, and taking notes and thinking while they are watching, basically, every student will see more than 2 times, some students even fast forward, focus on the parts that he most wants to see, or rewind the video to see where he doesn't understand, or pause the video to think.

2) Practice: The students usually simulate the circuit wiring or mechanical installation, because the interactive virtual simulation tool software can simulate the work environment and machinery according to the business process, and support the students to simulate the operation and prepare for the training operation; the students also use the test bank to test to learn they own learning situation.

\section{Interactive Behavior}

1) Teacher-student interaction: Mainly, the teacher raises some questions from textbooks in the classroom, named students to answer, if the student answers correctly will be given a certain score reward; or if students are willing to answer questions or raise questions, they can click the button of raise hands on the pads to attract the attention of the teacher

2) Student-student interaction: Students in the collaborative learning environment of stereoscopic teaching materials to discuss the issues of communication or to cooperate to learn for a common learning task.

\section{E. Students' Interest and Attitude}

1) Students' reaction when using: students usually have some impatience, when teacher controls their pads to use stereoscopic teaching materials in unified progress, but if the teacher allows the students to watch the video or simulate the operation by themselves, they will be very interested in a series of self-operation; When reviewing the old knowledge, most of the students will only see once, and the attitude is not serious, learning new knowledge, will be very interested, and the overall attitude is very serious.

2) Function application: the stereoscopic teaching materials can provide rich digital resources, diverse knowledge presentation methods, especially augmented reality technology and virtual simulation technology in the use of teaching, in which students are particularly interested, always scan the AR logo and virtual simulation operation happily; teacher can share students' excellent learning outcomes to every student in class by evaluation function system , which will improve students' interest in learning and correct learning attitude, because the way is related to students themselves, everyone wants to be selected as the excellent student.

Through the above analysis, it can be concluded that the function and effect of stereoscopic teaching materials in the application of secondary vocational education training courses mainly reflected in the classroom interaction, maintaining classroom discipline, evaluation, practice and simulation operations and so on; the effective application time of stereoscopic teaching materials in classroom teaching, mainly to arouse the students' memory of the content of the previous class to connect new knowledge, consolidate the old knowledge, understand new knowledge and simulation operation, etc.; As a new learning resources, it can enhance the effect of classroom interaction, improve the teaching quality, to a large extent stimulate students' interest in learning.

\section{CONCLUSION}

This paper firstly analyzes the structure and constituent elements of the Stereoscopic Teaching Materials from the view of teaching environment, and then from the perspective of the application of information technology in teaching, analyzes the Stereoscopic Teaching Material, as a new information technology, becoming a new teaching method and been applied in the Process and Method of Practical Teaching of Secondary Vocational Education. At the implementation level, how to use Stereoscopic Teaching Materials to Promote the Effectiveness of Vocational Teaching, need to observe and summarize the analysis.

\section{REFERENCES}

[1] Ronghuai Huang, Fang Guo.Design and Development of Stereoscopic Teaching Materia [J]. Modern Educational Technology, 2008,10: 105109.

[2] Haoyu Zhang. Reflections on the Construction of Stereoscopic Teaching Materia [J]. Journal of Chongqing University of Arts and Science (Natural Science Edition),2008,01:87-88.

[3] Jiangjiang Wei. Thinking and Practice of Stereoscopic Teaching Materia Construction [J]. Technology and Tublishing, 2011,09:30-32.

[4] Liming Ding. On the Construction of Stereoscopic Teaching Materia [J]. Higher vocational education (Journal of Tianjin Polytechnic University),2008,06:47-49. 